RESPIRATORY INFECTION

\title{
Inflammatory response associated with pulmonary complications in non-HIV immunocompromised patients
}

\author{
C Agustí, A Rañó, M Rovira, X Filella, N Benito, A Moreno, A Torres
}

Thorax 2004;59:1081-1088. doi: 10.1136/thx.2004.030551

See end of article for authors' affiliations

Correspondence to: Dr A Torres, Servei de Pneumologia, Hospital Clínic, Villarroel 170 , 08036 Barcelona, Spain; atorres@medicina.ub.es

Received 30 June 2004 Accepted 26 July 2004
Background: A study was undertaken to evaluate the local and systemic inflammatory response associated with pulmonary complications in immunocompromised patients and potential implications regarding severity and prognosis.

Methods: Levels of different inflammatory mediators were measured in the bronchoalveolar lavage (BAL) fluid and serum on days 1 and 4 after the identification of the pulmonary complication in 127 patients with different immunosuppressive conditions.

Results: Pulmonary complications were characterised by a high percentage of neutrophils and increased levels of tumour necrosis factor (TNF)- $\alpha$, interleukin (IL)- 6 , IL-8 and IL-10 in the BAL fluid and high serum levels of TNF- $\alpha, \mathrm{IL}-6$, and plasma C-reactive protein (CRP). The inflammatory response was similar in the different groups of immunocompromised patients evaluated. The levels of proinflammatory cytokines were higher in patients with pulmonary infections, particularly those of bacterial aetiology. Patients with a more severe pulmonary infection had a more intense local and systemic inflammatory response. A BAL fluid IL-6 level of $>40 \mathrm{pg} / \mathrm{ml}$ was an independent predictor of mortality (OR $4.65,95 \% \mathrm{Cl} 1.3$ to 16.1 ), together with a need for mechanical ventilation (OR 13.5, 95\% Cl 3.2 to 57.3). Patients who died had persistently high levels of CRP on day 4.

Conclusions: The evaluation of the inflammatory response, particularly the determination of IL- 6 levels in the BAL fluid and CRP in the serum, may be useful for deciding the appropriate management of pulmonary complications in immunocompromised patients.
D espite progress in diagnostic tools and therapeutic options, pulmonary complications-particularly lung infections in immunocompromised (IC) patients-still carry a high morbidity and mortality. ${ }^{1}$ Lung infections are characteristically associated with a striking inflammatory response aimed at controlling the proliferation of microorganisms and avoiding further derangement of the lung parenchyma. Thus, proinflammatory cytokines such as tumour necrosis factor (TNF)- $\alpha$, interleukin (IL)- 1 , and IL-8 facilitate the chemotaxis and activation of neutrophils in sites of infection, ${ }^{2}$ and IL- 6 is a potent inducer of the acute phase protein response. By contrast, IL-10, the most potent antiinflammatory cytokine, inhibits monocyte release of different proinflammatory cytokines and tries to counterbalance the host proinflammatory response. ${ }^{34}$ The evaluation of the inflammatory response in patients with pulmonary infections has been relevant for understanding the pathogenesis, as a potential clinical marker of severity, and for designing future immunomodulatory treatments. Both proinflammatory and counter-inflammatory cytokines have been correlated with the severity of the pulmonary infection determined by the APACHE II score and also with prognosis. ${ }^{5}$ Different studies have shown that levels of IL-6 also correlate with the severity and prognosis of the pulmonary infection. ${ }^{6}$ Interestingly, C-reactive protein (CRP), an IL-6 dependent acute phase protein, has also been shown to be a useful clinical marker in pneumonia. A persistently high or rising CRP level would suggest antibiotic treatment failure or the development of infective complications. ${ }^{7}$

Most of the studies evaluating the role of the local and systemic inflammatory response in pulmonary infections were performed in immunocompetent patients. ${ }^{8}$ The characteristics and relevance of the cytokine response to pulmonary complications in IC patients and its potential influence in the course and prognosis of the disease are largely unknown. We hypothesised that proinflammatory and counter-inflammatory cytokines involved in the inflammatory response in non-IC patients are also relevant in IC patients and may have an impact on the prognosis of the disease.

We have recently reported the clinical characteristics and diagnostic yield of different non-invasive and bronchoscopic techniques and the prognostic factors in a population of nonHIV IC patients with pulmonary infiltrates. ${ }^{10}$ The present study, based mainly on this population, was conducted to evaluate the characteristics of the inflammatory response associated with pulmonary complications. To do so we performed determinations of relevant proinflammatory and counter-inflammatory cytokines in bronchoalveolar lavage (BAL) fluid and serum. We were particularly interested to establish potential relationships between the characteristics of the inflammatory response and the specific aetiology and outcome of the pulmonary complication, and to identify potential clinical markers to facilitate the management of these often lethal complications.

\section{METHODS}

\section{Patients}

This observational study included 127 consecutive IC patients evaluated between January 1998 and July 2002, admitted to a third level University Hospital with a first episode of pulmonary infiltrates (table 1 ). Clinical, chest radiographic and laboratory findings and the Acute Physiology and

Abbreviations: BAL, bronchoalveolar lavage; BAS, bronchial aspirate; CRP, C-reactive protein; GVHD, graft versus host disease; HM, haematological malignancy; HSCT, haematopoietic stem cell transplantation; IC, immunocompromised; ICU, intensive care unit; IL, interleukin; PSB, protected specimen brush; SOT, solid organ transplantation; TNF, tumour necrosis factor 
Chronic Health Evaluation (APACHE) II score $^{11}$ were recorded when symptoms/signs of pulmonary complication were first noticed (day 1). Blood and sputum samples were also collected for culture. The bronchoscopic procedures performed included protected specimen brush (PSB), bronchial aspirate (BAS), and bronchoalveolar lavage (BAL). BAL was performed by infusing three aliquots (50 ml each) of sterile saline solution in the involved lobe in patients with localised pulmonary infiltrates and in the middle lobe or lingula in patients with diffuse pulmonary infiltrates. The first retrieved aliquot of BAL fluid was discarded. The recovered BAL fluid was mixed and sent to the laboratory for cytological and microbiological examination and measurements of cytokine levels.

Although the primary intention was to perform a fibreoptic bronchoscopy (FOB) in all patients, their clinical status and the criteria of the physician in charge affected the ultimate decision. All patients were on antibiotic treatment at inclusion according to standard guidelines.

Cytokine levels in IC patients were compared with those observed in 10 healthy subjects without respiratory disease who underwent bronchoscopy and gave informed consent to complete examination with BAL. The ethics committee of the hospital approved the study protocol and informed consent was obtained from all patients.

\section{Diagnostic criteria}

Bacterial pneumonia was diagnosed whenever blood or sputum samples grew pathogenic bacteria. Similarly, when a quantitative bacterial culture from BAS, BAL fluid, or PSB specimens grew more than $10^{5}, 10^{4}$, or $10^{3} \mathrm{cfu} / \mathrm{ml}$, respectively, the diagnosis of bacterial pneumonia was established. Any growth of facultative pathogenic bacteria such a Streptococcus viridans and coagulase negative Staphylococccus was considered irrelevant. Cytomegalovirus and other viruses were considered to be pathogens if they were isolated from BAL fluid or when inclusion bodies were present on histopathological evaluation. Pneumocystis carinii (PCP) was diagnosed by a positive Gomori methenamine silver stain. The identification of Legionella spp and mycobacteria was accepted as a definite diagnosis regardless of colony counts. Fungal pneumonia was diagnosed in the presence of a compatible clinical and radiographic pattern if fungal hyphae were identified by culture or by cytological evaluation of a

\begin{tabular}{ll}
$\begin{array}{l}\text { Table } 1 \text { Underlying diseases of the study } \\
\text { population ( } \mathrm{n}=127)\end{array}$ \\
\hline
\end{tabular}

BM, bone marrow; PBSC, peripheral blood stem cell. *Treated with chemotherapy. †Others: myelodysplastic syndrome (2), non-Hodgkin's disease (2), multiple myeloma (1).
Gram stain in at least two different respiratory samples, or when there was histological evidence of fungal pneumonia or positive blood cultures.

Non-infectious pulmonary infiltrates were considered when the clinical data did not suggest an infectious aetiology, no microbiological agents were isolated in any processed sample, and the clinical course and response to treatment were in accordance with an alternative non-infectious aetiology.

\section{Inflammatory response}

BAL fluid was centrifuged at $1800 \mathrm{rpm}$ for 10 minutes and the supernatant was frozen at $-70^{\circ} \mathrm{C}$ until further processing. TNF- $\alpha$, IL-1 $\beta$, IL-6, IL-8, and IL-10 levels were measured in BAL supernatant on day 1 and in serum on days 1 and 4 using an enzyme linked immunosorbent assay (ELISA) based on the quantitative immunometric sandwich enzyme immunoassay technique (Enzyme Amplified Sensitivity Immunoassay (EASIA); Medgenix Diagnostics, Fleurus, Belgium) and PerSeptive; Framingham, MA, USA). The following values were regarded as the upper limits for cytokine serum concentrations in normal controls in our laboratory: TNF- $\alpha$ : 20 pg/ml, IL-1 $\beta$ : 15 pg/ml, IL-6: 20 pg/ml, IL-8: $10 \mathrm{pg} / \mathrm{ml}$, IL-10: $5 \mathrm{pg} / \mathrm{ml}$. The sensitivity of the technique allows the detection of levels as low as $2 \mathrm{pg} / \mathrm{ml}$ for IL-1 $\beta$, IL-6, and IL- 8 and $3 \mathrm{pg} / \mathrm{ml}$ for TNF- $\alpha$ and IL- 10 . Total and differential cell counts of the BAL fluid were performed as described elsewhere. ${ }^{12}{ }^{13}$ Plasma CRP levels were measured on days 1 and 4 by immunonephrometry (normal value $<0.8 \mathrm{mg} / \mathrm{dl}$, lower limit of detection $0.0175 \mathrm{mg} / \mathrm{dl})$.

\section{Statistical analysis}

The primary objective of this study was to evaluate the local (lung) and systemic (serum) inflammatory response associated with pulmonary complications in IC patients and its potential implications regarding severity and prognosis. Secondary objectives were to assess whether the inflammatory response varies according to the type of immunosupression or the concrete aetiology of the pulmonary infiltrate. Continuous variables are summarised as mean (SD) or median values, depending on their homogeneity. As the cytokines and CRP values were not normally distributed, they were expressed as median values with $25-75$ th interquartiles. Linear correlations between quantitative variables (such as cytokines and APACHE II score) were analysed using Spearman's correlation coefficient.

The influence of several variables known to be potential predictors of outcome according to the literature ${ }^{10}$ were assessed using the Mann-Whitney U test or Student's $t$ test for continuous variables, the $\chi^{2}$ test for categorical variables, and the Fisher's exact test in the case of small expected frequencies. Some continuous variables were dichotomised. In order to optimise the threshold that would discriminate between survivors and non-survivors, the formula for threshold computation based on the median value (that is, the 50th percentile) was used. This included the delay in establishing a specific diagnosis of the pulmonary infiltrates $(<$ or $\geqslant 7$ days), age ( $<$ or $\geqslant 64$ years), and APACHE II score $(</ \geqslant 18)$. Cytokines associated with mortality in the MannWhitney U or Kruskal-Wallis tests were also categorised. Receiver operator characteristic (ROC) curve analysis was used to identify optimal cut off values.

Thereafter, a multiple logistical regression analysis with a conditional stepwise forward model was applied to the variables found to be significantly associated with death $(\mathrm{p}<0.01)$. Adjusted odds ratios $(\mathrm{OR})$ with $95 \%$ confidence intervals (CI) were computed for variables independently associated with mortality. All $\mathrm{p}$ values reported are two tailed 
Table 2 Demographic and clinical characteristics of the three groups of immunocompromised patients studied $(n=127)$

\begin{tabular}{lllll}
\hline Variable & $\begin{array}{l}\text { HSCT } \\
\text { (n=40) }\end{array}$ & $\begin{array}{l}\text { HM } \\
\text { (n=53) }\end{array}$ & $\begin{array}{l}\text { SOT } \\
(\mathbf{n = 3 4 )}\end{array}$ & p value \\
\hline Categorical* & & & & \\
Sex (M/F) & $27 / 13$ & $32 / 21$ & $26 / 8$ & 0.3 \\
$\quad$ Neutropenia & $18(47)$ & $23(45)$ & - & 0.001 \\
Bilateral infiltrates on chest radiograph & $24(60)$ & $27(51)$ & $18(53)$ & 0.6 \\
Infectious aetiology & $20(65)$ & $32(78)$ & $21(72)$ & 0.4 \\
Nosocomial pneumonia & $14(70)$ & $18(56)$ & $15(71)$ & 0.4 \\
Bacteraemia & $4(10)$ & $6(11)$ & $2(6)$ & 0.7 \\
GVHD & $19(52)$ & - & $9(30)$ & 0.05 \\
Delay in diagnosis $\geqslant 7$ days & $19(63)$ & $13(36)$ & $11(41)$ & 0.07 \\
Inadequate empirical treatment & $13(68)$ & $13(42)$ & $8(40)$ & 0.1 \\
Mechanical ventilation & $16(40)$ & $17(33)$ & $18(52)$ & 0.1 \\
Undiagnosed & $9(23)$ & $12(23)$ & $5(15)$ & 0.6 \\
Mortality & $16(40)$ & $14(26)$ & $11(32)$ & 0.4 \\
Continuous $\dagger$ & & & & \\
Age (years) & $42(12)$ & $53(18)$ & $50(14)$ & 0.005 \\
APACHE II & $16(6)$ & $17(7)$ & $18(7)$ & 0.4 \\
Creatinine (mg/l) & $1.6(1.5)$ & $1.1(0.4)$ & $3.1(2.1)$ & $<0.0001$ \\
Albumin (g/l) & $30(5)$ & $31.7(5)$ & $31.8(6)$ & 0.6 \\
PaO $/$ Fio (mm Hg) & $287(106)$ & $286(97)$ & $238(142)$ & 0.2 \\
\hline
\end{tabular}

HSCT, haematopoietic stem cell transplantation; HM, haematological malignancies; SOT, solid organ transplantation; GVHD, graft versus host disease.

*Data are presented as $\mathrm{n}(\%)$ unless otherwise indicated.

†Values are expressed as mean (SD).

$\ddagger$ Median value (50th percentile) for the whole population.

Neutropenia was defined as a granulocyte count of $<1000$ cells $/ \mu$.

and a value of $<0.05$ was considered statistically significant All statistics were calculated using the SPSS statistical package Version 10.0 (SPSS Inc, Chicago, IL, USA).

Table 3 Aetiology of pulmonary infiltrates in the study population

\begin{tabular}{|c|c|c|}
\hline & Cases & Mortality \\
\hline Infectious & 73 & $33(45 \%)$ \\
\hline Bacterial & 23 & $8(35 \%)$ \\
\hline$S$ aureus & 8 & \\
\hline$S$ pneumoniae & 1 & \\
\hline E faecium & 1 & \\
\hline E coli & 3 & \\
\hline$P$ aeruginosa & 3 & \\
\hline A baumanii & 3 & \\
\hline$S$ marcescens & 2 & \\
\hline$P$ mirabilis & 2 & \\
\hline Fungal & 24 & $14(58 \%)$ \\
\hline Aspergillus spp & 16 & \\
\hline Candida spp & 7 & \\
\hline$S$ prolificans & 1 & \\
\hline Viral & 16 & $6(38 \%)$ \\
\hline Influenza A virus & 5 & \\
\hline Cytomegalovirus & 4 & \\
\hline Parainfluenza virus type 3 & 2 & \\
\hline Respiratory syncytial virus & 4 & \\
\hline Virus herpes simplex-1 & 1 & \\
\hline Others & 4 & $1(25 \%)$ \\
\hline$P$ carinii & 2 & \\
\hline L pneumophila & 2 & \\
\hline Mixed infections & 6 & $4(67 \%)$ \\
\hline Non-infectious & 28 & $5(18 \%)$ \\
\hline Pulmonary oedema & 9 & \\
\hline DAH & 8 & \\
\hline $\begin{array}{l}\text { Pulmonary involvement of Hodgkin's } \\
\text { disease }\end{array}$ & 5 & \\
\hline COP & 3 & \\
\hline Others* & 3 & \\
\hline Undetermined & 26 & $3(12 \%)$ \\
\hline
\end{tabular}

DAH, diffuse alveolar haemorrhage; $C O P$, cryptogenic organising pneumonia; CMV, cytomegalovirus.

*Other non-infectious aetiologies: one each of alveolar proteinosis, bleomycin toxicity and sarcoidosis.

\section{RESULTS}

\section{Patients}

The study population comprised 53 patients with haematological malignancies (HM) treated with chemotherapy, 40 haematopoietic stem cell transplant (HSCT) recipients, and 34 patients who had received different solid organ transplants (SOT) (table 1). No previous pulmonary comorbidities were recorded among the patients included. The immunosuppressive treatment received was in accordance with the established protocols for both haematological and SOT patients, but it might differ in a particular patient if rejection of the allograft was present.

The demographic data and clinical characteristics of the 127 patients studied are shown in table 2 . Eighty five patients $(67 \%)$ were transferred to an ICU area and 51 of them $(41 \%)$ required mechanical ventilation. As expected, patients in the HSCT group were younger (42 (12) years) and patients in the SOT group had higher levels of creatinine ( $40 \%$ of them were renal transplant patients). The main clinical data-including the severity of the pulmonary complication assessed by the APACHE II score or the requirement for mechanical ventilation-were similar in the three groups of patients. Neutropenia (defined as a granulocyte count of $<1000$ cells $/ \mu \mathrm{l}$ ) was more prevalent in the HSCT and HM groups and the presence of graft versus host disease (GVHD) was more common in the HSCT group (table 2).

\section{Aetiology and outcome of the pulmonary complications}

Overall, a definite aetiology could be established in 101 of the 127 patients $(80 \%)$, being of infectious origin in $73(58 \%)$ and of non-infectious origin in $28(22 \%)$. The aetiology of the pulmonary infiltrate remained undiagnosed in 26 patients $(20 \%)$. Crude mortality was $32 \%(41 / 127)$ and was similar in the three groups of patients (table 2). The aetiology of the pulmonary infiltrate and the associated mortality are shown in table 3. Fungi (particularly Aspergillus spp, $\mathrm{n}=13$ ) and bacteria (particularly Staphyloccocus spp, $\mathrm{n}=8$ ) were the most common micro-organisms causing pulmonary infiltrates; pulmonary oedema and diffuse alveolar haemorrhage were the most common causes of non-infectious pulmonary 
Table 4 Concentrations of neutrophils (in BAL fluid), cytokines $(\mathrm{pg} / \mathrm{ml}$ in BAL fluid and serum), and CRP ( $\mathrm{mg} / \mathrm{dl}$ in serum) in the three groups of immunocompromised patients studied

\begin{tabular}{|c|c|c|c|c|}
\hline Variable & $\begin{array}{l}\text { HSCT } \\
(n=40)\end{array}$ & $\begin{array}{l}H M \\
(n=53)\end{array}$ & $\begin{array}{l}\text { SOT } \\
(n=34)\end{array}$ & p value \\
\hline \multicolumn{5}{|l|}{ BAL fluid } \\
\hline Neutrophils (\%) & $9(0-82)$ & $5(0-75)$ & $33(0-95)$ & 0.001 \\
\hline Neutrophil $\left(\times 10^{9}\right.$ cells $\left./ /\right)$ & $0.55(0.1)$ & $0.6(0.3)$ & $2.1(1.6)$ & 0.001 \\
\hline TNF- $\alpha$ & $9(1-27)$ & $7(1-30)$ & $5(1-8)$ & 0.9 \\
\hline IL-1 $\beta$ & $30(9-68)$ & $23(4-44)$ & $48(11-71)$ & 0.3 \\
\hline IL-6 & 53 (12-262) & $161(40-887)$ & $111(6-515)$ & 0.1 \\
\hline IL-8 & $58(18-445)$ & $80(38-248)$ & $309(59-561)$ & 0.08 \\
\hline IL-10 & $1(1-8)$ & $2(1-11)$ & $2(2-14)$ & 0.6 \\
\hline \multicolumn{5}{|l|}{ Serum (day 1) } \\
\hline TNF- $\alpha$ & $65(38-118)$ & $58(29-138)$ & $56(31-92)$ & 0.8 \\
\hline IL-1 $\beta$ & $1(1-7)$ & $1(1-10)$ & $1(1-20)$ & 0.4 \\
\hline IL-6 & $123(62-441)$ & $246(63-674)$ & $99(28-261)$ & 0.1 \\
\hline IL-8 & $58(17-81)$ & $84(25-205)$ & $79(20-146)$ & 0.4 \\
\hline IL-10 & $17(92-72)$ & 30 (17-92) & $55(12-178)$ & 0.5 \\
\hline CRP & $7.2(3.9-16.3)$ & $17.6(10-31.4)$ & $14.1(6.7-18.8)$ & 0.006 \\
\hline \multicolumn{5}{|l|}{ Serum (day 4) } \\
\hline TNF- $\alpha$ & $57(31-102)$ & $44(24-65)$ & $44(23-84)$ & 0.4 \\
\hline IL-1 $\beta$ & $1(1-3)$ & $1(1-7)$ & $1(1-2)$ & 0.2 \\
\hline IL-6 & $26(8-146)$ & $77(19-516)$ & $11(9-112)$ & 0.3 \\
\hline IL-8 & $38(29-111)$ & $31(4-97)$ & $71(23-164)$ & 0.3 \\
\hline IL-10 & $10(6-26)$ & $13(5-21)$ & $53(16-106)$ & 0.07 \\
\hline CRP & $5.6(1.1-12.7)$ & $10.4(3.7-19.3)$ & $6.6(1.5-16.6)$ & 0.2 \\
\hline
\end{tabular}

infiltrates. Pulmonary infections carried a higher mortality $(45 \%)$ than non-infectious pulmonary complications (18\%; $\mathrm{p}=0.012$ ). The diagnostic yield of the different non-invasive and bronchoscopic techniques used in the study was as follows: blood cultures, 20/123 (17\%); sputum culture, 22/58 (38\%); PSB, 23/102 (22\%); BAS, 33/70 (47\%); and BAL 58/ $115(51 \%)$.

\section{Pulmonary and systemic inflammatory response}

Fibreoptic bronchoscopy (FOB) was performed in 116 of the 127 patients, and in 112 of them BAL fluid samples were obtained for microbiological examination, differential cell counts, and determination of cytokine levels. Blood samples for cytokine determinations were obtained from all patients. There were no major complications resulting from FOB.

When the local and systemic inflammatory responses in healthy controls and the whole group of IC patients were compared, increased BAL fluid levels of TNF- $\alpha(0 \vee 7 \mathrm{pg} / \mathrm{ml}$; $\mathrm{p}<0.001)$, IL-6 ( $0 \vee 95 \mathrm{pg} / \mathrm{ml} ; \mathrm{p}<0.001)$, IL-8 $(0 \vee 97 \mathrm{pg} / \mathrm{ml})$, IL-10 (0 $\vee 5 \mathrm{pg} / \mathrm{ml} ; \mathrm{p}<0.001)$ and, to a lesser degree, serum $\mathrm{TNF}-\alpha(18 \vee 58 \mathrm{pg} / \mathrm{ml} ; \mathrm{p}=0.002)$ and IL-6 (4 $\vee 143 \mathrm{pg} / \mathrm{ml}$; $\mathrm{p}<0.001)$ were observed in IC patients.

As shown in table 4, the inflammatory response in both the lung and the serum was comparable in the three groups of IC patients. However, patients with SOT had a higher number of BAL fluid neutrophils and patients with HSCT had the lowest levels of serum CRP on day 1 . The inflammatory response in patients with haematological diseases (HSCT and HM) was similar when neutropenic and non-neutropenic patients were compared (data not shown).

There were significant correlations between the percentage of BAL neutrophils and BAL fluid concentrations of TNF- $\alpha$ $(r=0.3, \mathrm{p}=0.003), \quad$ IL-6 $\quad(r=0.36, \mathrm{p}<0.001)$, and IL-8 $(r=0.45, \mathrm{p}<0.001)$. In contrast, levels of the anti-inflammatory cytokine IL-10 did not correlate with any of the proinflammatory counterparts. Individually, poor correlations were observed between BAL fluid and serum levels, with a rho coefficient lower than 0.1 for all the cytokines evaluated except for IL-6 $(r=0.44, \mathrm{p}<0.001)$.

\section{Inflammatory response and the aetiology of pulmonary infiltrates}

Interestingly, when the whole population of IC patients was pooled together, the inflammatory response in patients with pulmonary infiltrates of an infectious aetiology was more intense than the response in patients with non-infectious complications. This increased inflammatory response was characterised by higher levels of BAL fluid levels of IL-6 (176 $v 53 \mathrm{pg} / \mathrm{ml} ; \mathrm{p}=0.016)$ and IL-8 (135 $v 38 \mathrm{pg} / \mathrm{ml} ; \mathrm{p}=0.045)$ and serum levels of TNF- $\alpha$ on day 1 (75 $v 47 \mathrm{pg} / \mathrm{ml}$; $\mathrm{p}=0.038)$. In addition, serum IL-6 levels ( $112 \vee 26 \mathrm{pg} / \mathrm{ml}$; $\mathrm{p}=0.05)$ and CRP levels on day 4 ( $11 \vee 6.6 \mathrm{mg} / \mathrm{dl} ; \mathrm{p}=0.05)$ were significantly higher in the infectious group. When the group with infectious complications were divided into specific aetiologies (bacterial, fungal and viral), we observed a trend towards a more intense pulmonary inflammatory response in those with bacterial infections (fig 1). However, none of the inflammatory mediators evaluated was specific enough to clearly distinguish between bacterial, fungal or viral infections. No differences in local or systemic inflammatory response were observed between Gram positive and Gram negative bacterial pneumonia. However, the 12 patients $(9.4 \%)$ with a documented spread of infection in the bloodstream had higher serum levels of IL- 6 on day 1 than the 115 patients $(90.6 \%)$ without bacteraemia $(720 \mathrm{v}$ $119 \mathrm{pg} / \mathrm{ml}, \mathrm{p}<0.01$ ).

\section{Inflammatory response and severity of pulmonary complication}

Proinflammatory cytokines in BAL fluid were significantly associated with the severity of the pulmonary complication assessed by the APACHE II score (TNF- $\alpha$ : $r=0.2, \mathrm{p}<0.04$; IL-6: $r=0.36, \mathrm{p}<0.001$; IL-8: $r=0.33, \mathrm{p}<0.001)$. Similarly, non-survivors had a higher inflammatory response at 

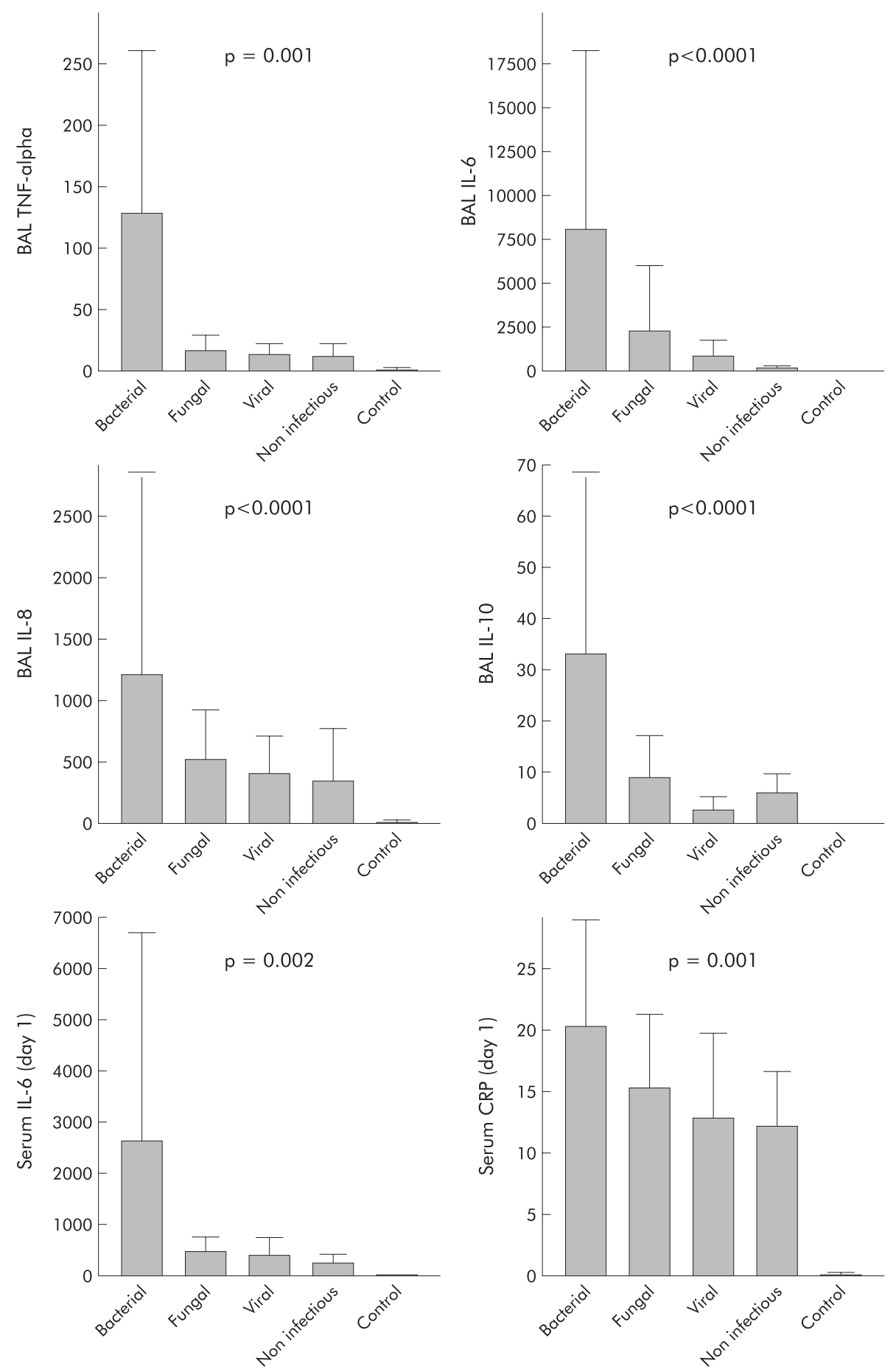

Figure 1 Concentrations of cytokines and C-reactive protein (CRP) in BAL fluid and serum in relation to type of aetiology (bacterial, $n=22$; viral, $n=15$; fungal, $n=24$; non-infectious, $n=25$; control $n=10$ ). Bars and error bars represent mean (SE). Cytokines are expressed as $p g / m l$ and CRP as $\mathrm{mg} / \mathrm{dl}$. Differences between aetiologies were analysed by the Mann-Whitney test.

diagnosis, both locally and systemically (table 5). Serum levels of IL-6 on day 4 also discriminated between survivors and non-survivors and a similar trend was observed in serum CRP levels (fig 2). Thus, although there was no difference in serum CRP levels between survivors and non-survivors on day 1 (13.8 (11) $v 16.2$ (10) mg/dl), CRP levels in patients who died remained high on day 4 (15.2 (12) mg/dl) and tended to return to normal in survivors $(8.6(6.5) \mathrm{mg} / \mathrm{dl}$, $\mathrm{p}=0.02$; fig 2 ). There was a close correlation between serum levels of IL- 6 and CRP on admission $(r=0.65, \mathrm{p}<0.001)$ and on day $4(r=0.87, \mathrm{p}<0.001)$.

As expected, the inflammatory response in ventilated patients was more intense than in non-ventilated patients: BAL fluid IL-8 $(p=0.003)$, serum IL-6 $(p<0.001)$, IL-8 $(\mathrm{p}<0.001)$ and IL-10 $(\mathrm{p}<0.001)$ on day 1 , and serum IL-6 $(\mathrm{p}=0.009)$ and IL-10 $(\mathrm{p}=0.045)$ on day 4 . 
Table 5 Concentrations of neutrophils (in BAL fluid), cytokines (in BAL fluid and serum in pg/ml), and CRP (in serum in mg/dl) in relation to hospital mortality

\begin{tabular}{|c|c|c|c|c|c|c|c|c|c|}
\hline & \multicolumn{6}{|l|}{ Day 1} & \multirow{2}{*}{\multicolumn{3}{|c|}{$\frac{\text { Day } 4}{\text { Serum }}$}} \\
\hline & \multicolumn{3}{|l|}{ BAL fluid } & \multicolumn{3}{|l|}{ Serum } & & & \\
\hline & $\begin{array}{l}\text { Survivors } \\
(\mathrm{n}=77)\end{array}$ & $\begin{array}{l}\text { Non-survivors } \\
(\mathrm{n}=35)\end{array}$ & $p$ & $\begin{array}{l}\text { Survivors } \\
\text { ( } \mathrm{n}=77 \text { ) }\end{array}$ & $\begin{array}{l}\text { Non-survivors } \\
(\mathrm{n}=35)\end{array}$ & $\mathbf{p}$ & $\begin{array}{l}\text { Survivors } \\
(\mathrm{n}=77)\end{array}$ & $\begin{array}{l}\text { Non-survivors } \\
(n=24)\end{array}$ & $\mathbf{p}$ \\
\hline Neutrophils & $1.85(1.7)$ & $2.14(1.4)$ & 0.003 & $6.9(5.4)$ & $7.4(6.1)$ & NS & - & - & - \\
\hline Neutrophil (\%) & $6(1-30)$ & $21(7-43)$ & 0.024 & - & - & - & - & - & - \\
\hline TNF- $\alpha$ & $5(1-27)$ & 11 (5-29) & 0.05 & $56(36-102)$ & $72(35-174)$ & NS & $52(29-82)$ & $37(16-67)$ & NS \\
\hline IL-1 $\beta$ & $30(9-57)$ & $28(7-59)$ & NS & $1(1-6)$ & $3(1-40)$ & 0.05 & $1(1-6)$ & $1(1-42)$ & NS \\
\hline IL-6 & 67 (12-288) & $210(54-1121)$ & 0.024 & $78(36-299)$ & $322(140-905)$ & 0.001 & $42(10-153)$ & $212(20-763)$ & 0.05 \\
\hline IL-8 & 73 (31-299) & $204(46-874)$ & 0.05 & $44(18-116)$ & $108(76-275)$ & 0.006 & 38 (16-138) & 27 (8-97) & NS \\
\hline IL-10 & $1(1-11)$ & $3(1-13)$ & NS & $22(6-77)$ & $63(20-115)$ & 0.03 & $16(6-55)$ & $12(1-97)$ & NS \\
\hline CRP & - & - & - & $11.9(4.7-20)$ & $16.3(14.3-21.5)$ & NS & $5.5(1.3-16.3)$ & $15.17(12.3-18.2)$ & 0.024 \\
\hline
\end{tabular}

Data are presented as median (25-75th interquartile) or mean (SD). Neutrophil count is expressed as $\times 10^{9}$ cells $/$.

\section{Prognostic factors of pulmonary complications}

The following clinical and biological variables were included in the univariate analysis to determine predictive factors of mortality: age, sex, type of immunosuppression, inadequate empirical treatment, delay in diagnosis, presence of neutropenia or GVHD, requirement for mechanical ventilation, APACHE II score, radiographic pattern, biochemical and haematological parameters, serum CRP levels, and BAL fluid and serum levels of cytokines (table 6). Univariate analysis showed that an APACHE II score of $\geqslant 18$, need for mechanical ventilation, a delay in diagnosis of $\geqslant 7$ days, an infectious aetiology, inadequate empirical treatment, BAL fluid levels of TNF- $\alpha$, IL-6, IL-8, serum levels of IL-1 $\beta$, IL-6, IL-8, IL- 10 on day 1 , and serum CRP and IL- 6 levels on day 4 were associated with a poor prognosis. Multivariate statistical analysis showed that requirement for mechanical ventilation and a BAL fluid level of IL- 6 higher than $40 \mathrm{pg} / \mathrm{ml}$ were the only two variables associated with mortality (table 7 ). The simultaneous presence of these two factors was associated with a mortality rate of $77 \%$ ( 26 of 34 patients; OR $94,95 \%$ CI 11 to 805) while their absence was associated with a mortality rate of only $3 \%$ ( 1 of 30 patients; $p<0.001$ ).

\section{DISCUSSION}

This study supports the hypothesis that pulmonary complications in IC patients, particularly those with infections, are associated with increased levels of proinflammatory and counter-inflammatory cytokines. This inflammatory response correlates with the severity of the complication and may be of prognostic value.
Pathogen recognition by Toll-like receptors provokes rapid activation of innate immunity by inducing production of proinflammatory cytokines and upregulation of co-stimulatory molecules. ${ }^{14}$ We have evaluated the innate immune response in different groups of IC patients with pulmonary complications and have found that this response is similar to that seen in non-immunosuppressed patients-namely, raised levels of proinflammatory cytokines such as TNF- $\alpha$, IL-6 and IL-8 and also increased production of counterinflammatory mediators such as IL-10. The inflammatory response was more intense in patients with infections, particularly in those with bacterial pneumonia. This group had the highest values compared with non-infectious complications or a non-bacterial infection. The intensity of the local inflammatory response seems to be a good indicator of severity of the pulmonary complication in IC patients, as evidenced by the good correlation between the APACHE II severity score and the levels of various cytokines in the BAL fluid, and the higher levels of these markers in non-survivors than in survivors. A BAL fluid level of IL-6 of $>40 \mathrm{pg} / \mathrm{ml}$, together with the requirement for mechanical ventilation, was the only predictive factor of mortality in the multivariate analysis (OR 4.65). This indicates the relevance of the local inflammatory response in the outcome of pulmonary complications in IC patients. Interestingly, levels of serum IL-6 were particularly high in patients with documented bacteraemia, a finding also observed in immunocompetent patients with sepsis. ${ }^{15} 16$ In addition, we observed that a persistently high serum level of IL-6 over time discriminates between survivors and non-survivors. A similar trend was
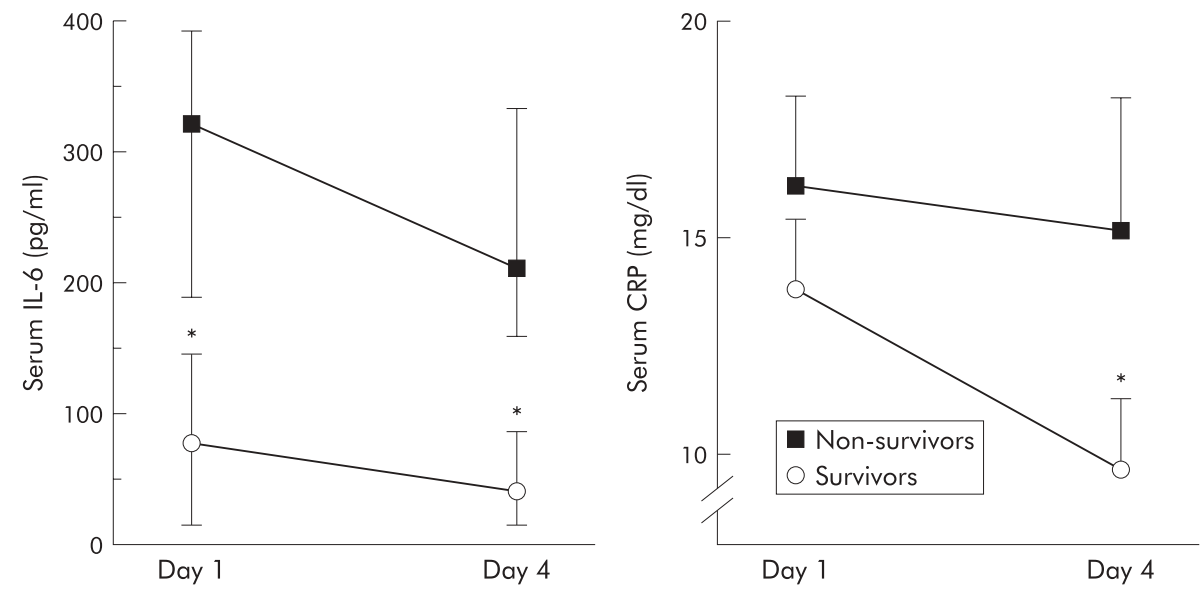

Figure 2 Evolution of serum levels of IL-6 (median and 25-75th interquartile range) and CRP (mean (SD)) in survivors and non-survivors. * $\mathrm{p}<0.05$. 


\begin{tabular}{|c|c|c|c|c|c|}
\hline Variable & $\begin{array}{l}\text { All patients } \\
(\mathrm{n}=127)\end{array}$ & $\begin{array}{l}\text { Survivors } \\
(\mathrm{n}=86)\end{array}$ & $\begin{array}{l}\text { Non-survivors } \\
(n=41)\end{array}$ & $\begin{array}{l}\text { OR } \\
(95 \% \mathrm{Cl})\end{array}$ & $p$ value \\
\hline $\operatorname{Sex}(M / F)$ & $85 / 42$ & $59 / 27$ & $26 / 15$ & $0.8(0.3$ to 1.7$)$ & 0.7 \\
\hline \multicolumn{6}{|l|}{ Type of immunosuppression } \\
\hline HSCT & $40(31)$ & $24(28)$ & $16(39)$ & - & 0.2 \\
\hline HM & $53(42)$ & $39(45)$ & $14(34)$ & - & 0.3 \\
\hline SOT & $34(27)$ & $23(27)$ & $11(27)$ & - & 1 \\
\hline \multicolumn{6}{|l|}{ Type of infection } \\
\hline Bacterial & $27(38)$ & $18(47)$ & $9(28)$ & - & 0.2 \\
\hline Fungal & $29(41)$ & $13(34)$ & $16(50)$ & - & 0.2 \\
\hline Viral & $14(20)$ & $7(18)$ & $7(22)$ & - & 0.7 \\
\hline Age $\geqslant 64$ years $^{*}$ & $66(53)$ & $45(54)$ & $21(53)$ & $0.9(0.4$ to 2.1$)$ & 1 \\
\hline Bilateral infiltrates on chest radiograph & $69(54)$ & $38(44)$ & $31(76)$ & $4(1.7$ to 8.9$)$ & 0.001 \\
\hline Neutropenia & 41 (34) & $26(32)$ & $15(37)$ & $1.3(0.6$ to 2.8$)$ & 0.5 \\
\hline GVHD & $28(43)$ & $17(40)$ & $11(46)$ & $1.2(0.4$ to 3.4$)$ & 0.8 \\
\hline Delay in diagnosis $\geqslant 7$ days* & $43(46)$ & $22(38)$ & $21(58)$ & $2.2(0.9$ to 5.2$)$ & 0.05 \\
\hline APACHE II score $\geqslant 18^{*}$ & $59(47)$ & $24(28)$ & $35(86)$ & $15(5.6$ to 40.4$)$ & $<0.0001$ \\
\hline Mechanical ventilation & $51(40)$ & $14(16)$ & 37 (93) & $62.5(16.9$ to 231$)$ & $<0.0001$ \\
\hline Infectious aetiology & 73 (72) & $40(63)$ & $33(87)$ & $3.7(1.3$ to 11.1$)$ & 0.012 \\
\hline Inadequate empirical treatment & $34(48)$ & $12(32)$ & $22(67)$ & $4.1(1.5$ to 11.3$)$ & 0.008 \\
\hline \multicolumn{6}{|l|}{ BAL fluid +} \\
\hline Neutrophils $>5 \%$ & $64(60)$ & $39(51)$ & $25(83)$ & $4.8(1.7$ to 14$)$ & 0.002 \\
\hline $\mathrm{TNF}-\alpha>4 \mathrm{pg} / \mathrm{ml}$ & $70(63)$ & $43(56)$ & 27 (77) & $2.7(1.1$ to 6.6$)$ & 0.036 \\
\hline $\mathrm{IL}-6>40 \mathrm{pg} / \mathrm{ml}$ & $71(63)$ & $43(55)$ & $28(80)$ & 3.1 (1.2 to 8.2$)$ & 0.01 \\
\hline $\mathrm{IL}-8>325 \mathrm{pg} / \mathrm{ml}$ & $33(31)$ & $18(24)$ & $15(47)$ & $2.8(1.1$ to 6.7$)$ & 0.02 \\
\hline \multicolumn{6}{|l|}{ Serum (day 1)† } \\
\hline $\mathrm{IL}-1 \beta>62 \mathrm{pg} / \mathrm{ml}$ & $5(7)$ & - & $5(21)$ & $3.7(2.5$ to 5.2$)$ & 0.003 \\
\hline $\mathrm{IL}-6>192 \mathrm{pg} / \mathrm{ml}$ & $48(66)$ & $27(55)$ & $21(88)$ & $5.7(1.5$ to 21.6$)$ & 0.008 \\
\hline IL- $8>75 \mathrm{pg} / \mathrm{ml}$ & $25(48)$ & $13(35)$ & $12(80)$ & $7.3(1.7$ to 31$)$ & 0.005 \\
\hline $\mathrm{IL}-10>10 \mathrm{pg} / \mathrm{ml}$ & $41(79)$ & $26(70)$ & $15(100)$ & 1.5 (1.2 to 2$)$ & 0.02 \\
\hline \multicolumn{6}{|l|}{ Serum (day 4) $\dagger$} \\
\hline $\mathrm{IL}-6>120 \mathrm{pg} / \mathrm{ml}$ & $19(36)$ & $12(28)$ & $7(64)$ & $4.3(1.1$ to 17.7$)$ & 0.04 \\
\hline $\mathrm{CRP}>5.6 \mathrm{mg} / \mathrm{dl}$ & $34(58)$ & $21(48)$ & $13(87)$ & $7.2(1.4$ to 35.3$)$ & 0.01 \\
\hline
\end{tabular}

also observed with plasma CRP levels, an acute phase protein synthesised by the liver that is mainly dependent on the IL-6 concentration. In our study persistently increased levels of CRP on day 4 predicted a poor outcome. This suggests that serial determination of specific cytokines, or even easily available laboratory tests such as CRP, may have clinical relevance and enhance the accuracy of clinical severity scores in pulmonary infections. ${ }^{6}{ }^{17}$

The following limitations have to be considered for the proper interpretation of the results in this study. Certainly, the cytokine levels and neutrophil counts in the BAL fluid suggest an efficient innate response to pathogens in our population. Activated innate immunity subsequently leads to effective adaptive immunity. The adaptive immune response is characterised by the clonal selection of antigen specific lymphocytes. Unfortunately, in the present study we did not collect information regarding adaptive immunity. However, the poor prognosis observed in some of the patients, as well as the severe immunosuppressive states, suggests that adaptive pathways may be impaired. Further studies focusing on the interactions between innate and adaptive immunity are needed to understand the complex host defence mechanisms against invading microbial pathogens.

Although the type of immunosuppression had no apparent influence in terms of outcome or levels of inflammatory

Table 7 Prognostic factors related to mortality (multivariate analysis)

\begin{tabular}{lll}
\hline Variable & OR $(95 \% \mathrm{Cl})$ & p value \\
\hline Mechanical ventilation & $13.5(3.2$ to 57.3$)$ & $<0.001$ \\
BAL IL-6 $>40 \mathrm{pg} / \mathrm{ml}$ & $4.65(1.3$ to 16.1$)$ & 0.015 \\
\hline
\end{tabular}

mediators (table 4), we cannot definitively rule out this factor in potentially affecting the innate immune response. Some of the confounding factors include the particular underlying disease, the immunosuppressive drugs or antibiotics received, the development of immunological complications such as GVHD, the presence of neutropenia, and the potential influence of a genetically determined inflammatory response. ${ }^{18} 19$ Another potential limitation of our study is that $41 \%$ of the patients received mechanical ventilation, and the expression of BAL fluid cytokines in patients with severe pneumonia receiving mechanical ventilation may be amplified by ventilator associated lung injury. ${ }^{20}$

Despite these potential weaknesses, patients with pulmonary complications showed a remarkably homogeneous inflammatory response. This response was similar in the different groups and confirms previous findings in nonimmunocompromised patients regarding the key function of proinflammatory cytokines in response to several respiratory pathogens, mainly bacteria. ${ }^{21}{ }^{22}$ The correlation between the intensity of the inflammatory response and the severity of the pulmonary complication has also been observed in immunocompetent patients. ${ }^{23}$ Differences between bacterial, viral, and fungal pneumonia in the intensity of the inflammatory response may be explained by more intense stimulation of cytokine production by the cell wall components released by killed bacteria such as endotoxin from Gram negative bacilli and lipoteichoic acid and bacterial peptidoglycan from Gram positive bacteria. ${ }^{24}{ }^{25}$ Although this finding could reveal the capacity of microbial agents to cause a more intense inflammatory response, we cannot rule out the possibility that the differences observed were the result of different severity of the pulmonary complication reflected by a significantly higher mortality in patients with an infectious aetiology. Characteristically, and similar to what has been observed in immunocompetent states, the inflammatory 
response in immunosuppressed patients is compartmentalised with poor correlations between BAL fluid and serum levels of cytokines. ${ }^{26}$ However, contrary to what has been described, ${ }^{4}$ BAL fluid levels of IL-10 in our study were lower than serum levels. IL-10 has important anti-inflammatory properties, ${ }^{27}$ it antagonises the generation of the Thl class of $\mathrm{T}$ cells and suppresses, among others, the production of IL$1 \beta$, TNF- $\alpha$, IL- 6 , and IL- 8 . The concentration of IL- 10 in the blood and in tissue compartments is often indicative of the magnitude of the inflammatory stress. Clearly, the mechanisms that determine the amount and balance of various proinflammatory and counter-inflammatory cytokines are largely unknown. As samples of BAL fluid samples were taken only once in our study, we cannot be sure whether some patients were able to mount a substantial counterinflammatory response at an earlier time point (a response that is subsequently downregulated when BAL is performed). Interestingly, in a group of patients with cystic fibrosis, Bonfield $e t a^{28}$ found that, unlike other counter-inflammatory mediators such as TNF soluble receptor (TNF-sR) or IL-1 receptor antagonist (IL-1 Ra), the BAL fluid levels of IL-10 were lower than in controls. This suggests that, in particular circumstances, there may be a dysfunction of important homeostatic mechanisms.

In summary, this study is the first attempt to evaluate prospectively the inflammatory response in a broad group of IC patients. The results obtained indicate that pulmonary complications in these patients are associated with a local and systemic inflammatory response which correlates with the severity of the pulmonary complication and is more intense in infections, particularly in bacterial pneumonia. IL-6 appears to reflect clinical severity better than any other cytokine, being a good predictor of mortality when measured in BAL fluid. Serial serum determinations of IL-6 and its acute phase protein CRP may help in the further selection of patients with a poor response to treatment.

\section{Authors' affiliations}

C Agustí, A Torres, Servei de Pneumologia, Hospital Clínic, Universitat de Barcelona, Spain

A Rano, Unitat de Cures Intensives, Althaia, Xarxa Assistencial de Manresa, Barcelona, Spain

M Rovira, Servei de Hematologia, Hospital Clínic, Universitat de Barcelona, Spain

X Filella, N Benito, A Moreno, Serveis de Bioquímica i Infeccions, Hospital Clínic, Universitat de Barcelona, Spain

Funding: SOCAP (Societat Catalana de Pneumologia), FUCAP (Fundació Catalana de Pneumologia), SEPAR (Sociedad Española de Neumología), Reg Gira (FIS-ISCIII-03/063) y Respira (FIS-ISCIII-RTIC03/11), grant FISS 2003/PI030113.

\section{REFERENCES}

1 Poe RH, Wahl GW, Qazi R, et al. Predictors of mortality in the immunocompromised patients with pulmonary infiltrates. Arch Intern Med 1986;146:1304-8.
2 Stevens DL. Cytokines: an updated compendium. Curr Opin Infect Dis 1995;8:175-80.

3 Dinarello CA. Proinflammatory and anti-inflammatory cytokines mediators in the pathogenesis of sheptic shock. Chest 1997;112(Suppl 6):321-9.

4 Glynn P, Coakley R, Kilgallen I, et al. Circulating interleukin 6 and interleukin 10 in community acquired pneumonia. Thorax 1999;54:51-5.

5 Taniguchi T, Koido Y, Aiboshi J, et al. A change in the ratio of interleukin-6 to interleukin-10 predicts a poor outcome in patients with systemic inflammatory response syndrome. Crit Care Med 1999;27:1262-4.

6 Antunes G, Evans SA, Lordan JL, et al. Systemic cytokine levels in communityacquired pneumonia and their association with disease severity. Eur Respir J 2002;20:990-5.

7 Smith RP, Lipworth BJ, Cree IA, et al. C-reactive protein: a clinical marker in community-acquired pneumonia. Chest 1995;108:1288-91.

8 Montón C, Torres A, El-Ebiary M, et al. Cytokine expression in severe pneumonia: a bronchoalveolar study. Crit Care Med 1999;27:1745-53.

9 Rañó A, Agustí C, Jiménez $P$, et al. Pulmonary infiltrates in non-HIV immunocompromised patients. A diagnostic approach using non-invasive and bronchoscopic procedures. Thorax 2001;56:379-87.

10 Rañó A, Agustí C, Benito N, et al. Prognostic factors of non-HIV immunocompromised patients with pulmonary infiltrates. Chest 2002;122:253-61.

11 Knauss W, Draper EA, Wagner DP, et al. APACHE II: a severity of disease classification system. Crit Care Med 1985;13:818-29.

12 Angrill J, Agustí C, Celis R, et al. Bronchial inflammation and colonization in patients with clinically stable bronchiectasis. Am J Respir Crit Care Med $2001 ; 164: 1628-32$.

13 Baver T, Montón C, Torres A, et al. Comparison of systemic cytokine levels in patients with acute respiratory distress syndrome, severe pneumonia, and controls. Thorax 2000:55:46-52.

14 Lien E, Ingalls R. Toll-like receptors. Crit Care Med 2002;30:S1-11.

15 Groeneveld ABJ, Tacx AN, Bossink AWJ, et al. Circulating inflammatory mediators predict shock and mortality in febrile patients with microbial infection. Clin Immunol 2003;106:106-15.

16 Kragsbjerg P, Holmberg H, Vikerfors T. Dynamics of blood cytokine concentrations in patients with bacteremic infections. Scand J Infect Dis 1996;28:391-8.

17 Agustí C, Rañó A, Filella $X$, et al. pulmonary infiltrates in patients receiving long-term glucocorticoid treatment: etiology, prognostic factors and associated inflammatory response. Chest 2003;123:488-98.

18 Min CK, Lee WY, Min DJ, et al. The kinetics of circulating cytokines including IL-6, TNF- $\alpha$, IL-8 and IL-10 following allogenic hematopoietic stem cell transplantation. Bone Marrow Transplant 2001;28:935-40.

19 Agusti C, Torres A. Dying from pneumonia: which gene is the culprit? Crit Care Med 2004;32:1225-6.

20 Ranieri VM, Suter PM, Tortorella C. Effect of mechanical ventilation on inflammatory mediators in patients with acute respiratory distress syndrome: a randomized controlled trial. JAMA 1999;282:54-6.

21 Nelson S, Mason CM, Kolls J, et al. Pathophysiology of pneumonia. Clin Chest Med 1995; 16:1-12.

22 Toikka P, Irjala K, Juven T, et al. Serum procalcitonin, C-reactive protein and interleukin-6 for distinguishing bacterial and viral pneumonia in children. Pediatr Infect Dis 2000;19:598-602.

23 Bonten M, Froon A, Gaillard C, et al. The systemic inflammatory response in the development of ventilator-associated pneumonia. Am J Respir Crit Care Med 1997; 156:1 105-13.

24 Tuomanen El, Austrian R, Masure HR. Pathogenesis of pneumococcal infection. N Engl J Med 1995;323:1280-4.

25 Jagger MP, Huo Z, Riches PG. Inflammatory cytokine (interleukin-6 and tumour necrosis factor alpha) release in a human whole blood system in response to Streptococcus pneumoniae serotype 14 and its capsular polysaccharide. Clin Exp Immunol 2002;130:467-74.

26 Dehoux MS, Boutten A, Ostinelli J, et al. Compartmentalized cytokine production within the human lung in the unilateral pneumonia. Am J Respir Crit Care Med 1994;150:710-6.

27 Oberholzer A, Oberholzer C, Moldawer LL. Interleukin-10: a complex role in the pathogenesis of sepsis syndromes and its potential as an anti-inflammatory drug. Crit Care Med 2002;30:S58-63.

28 Bonfield TL, Panuska JR, Konstan MW, et al. Inflammatory cytokines in cystic fibrosis lungs. Am J Respir Crit Care Med 1995;152:2111-8. 